\section{A Longitudinal Study of Early Childhood Caries and Associated Factors in Brazilian Children}

Fabiane Piva ${ }^{1}$, Joanna Tatith Pereira², Patrícia Blaya Luz ${ }^{3}$, Lina Naomi Hashizume ${ }^{4}$, Fernando Neves Hugo ${ }^{4}$, Fernando Borba de Araujo ${ }^{4}$

\author{
'ULBRA - Universidade Luterana \\ do Brasil, Campus Cachoeira do \\ Sul, Cachoeira do Sul, RS, Brazil \\ ${ }^{2} \mathrm{FSG}$ - Faculdade da Serra Gaúcha, \\ Caxias do Sul, RS, Brazil \\ ${ }^{3} \mathrm{PhD}$ in Dentistry, Porto \\ Alegre, RS, Brazil \\ ${ }^{4}$ UFRGS - Universidade Federal do Rio \\ Grande do Sul, Porto Alegre, RS, Brazil
}

Correspondence: Fabiane Piva, Rua Martinho Lutero, 301, Distrito Universitário, 96501-595 Cachoeira do Sul, RS, Brasil. Tel: +55-51-92458839. e-mail: fabi.piva@ig.com.br

Key Words: early childhood caries, preschool children, longitudinal studies
Early childhood caries (ECC) affects children all over the world and has high prevalence and severity in preschool children. Different social, biological and behavioral factors compose a network of causal factors for ECC. The aim was to evaluate the association between socioeconomic variables and caries at baseline, and the presence of Streptococcus mutans and Lactobacillus spp. microorganisms with the progression of caries lesions after two years of follow-up in a group of children. At baseline, 163 children (3-4 years old) living in the areas of 12 primary care services of the Hospital Group Conceição (GHC, Porto Alegre, RS, Brazil) were evaluated. After two years, 119 children were re-evaluated. Clinical examinations were conducted by calibrated examiners using the ICDAS criteria. A sociodemographic questionnaire was applied to the children's parents and saliva samples were collected from the children for microbiological analysis. Descriptive statistics and multivariate Poisson regression analysis were performed in the statistical analysis. The factors associated with the caries progression were marital status of mothers $(p=0.040)$, higher S. mutans counts $(p=0.031)$ and the presence of cavitated lesions at baseline $(p<0.001)$. The caries lesions progression in preschool children enrolled in primary health care was directly associated with marital status, presence of cavitated lesions at baseline and higher S. mutans counts at two-year follow-up.

\section{Introduction}

Dental caries is the most prevalent chronic disease in children and adolescents in developed as well as the developing countries (1). Although there has been a small reduction in caries prevalence in preschools, it remains high (2).

In Brazil, there is a public health system to which the whole population has access. Professionals from different areas of health work within this system, including dentists. Dentists' responsibilities in primary care include carrying out comprehensive dental care (health protection, prevention of diseases, diagnosis, treatment, rehabilitation and health maintenance) individually and collectively (3).

These actions for prevention and treatment of caries lesions in the first years of life should be an instrument for reducing the prevalence and incidence of caries in primary and permanent dentition (4).

Thus, evaluating the oral health of preschool children is important because the experience of caries in primary teeth has been considered the strongest predictor of caries in permanent teeth and this was confirmed by several longitudinal studies conducted in different countries $(1,5-8)$.

Longitudinal studies also showed that Streptococcus mutans and Lactobacillus levels are associated with increased experience of caries $(1,9)$.

Other longitudinal studies have associated the increase of children's caries with socioeconomic factors, such as low maternal education (10) and neighborhood disadvantage (6).

In Brazil, only one longitudinal study in southern region of the country has evaluated the oral condition of children at preschool age (8). The results did not differ from studies conducted in other countries. The results showed that the presence of dental caries at baseline can be considered a caries increment predictor, both in deciduous and in permanent teeth $(5,7,9,11)$ and that high levels of $S$. mutans at baseline were associated with higher incidence of carious lesions (9). In addition, only one study used diagnostic methods that consider non-cavitated lesions and their progression with time in preschool and the relationship of socioeconomic factors with the progression of dental caries in primary teeth (6).

The aim of this study was to determine the incidence and progression of carious lesions after two years of follow-up in preschool children enrolled in primary health care and to evaluate their association with demographic, 
socioeconomic and microbiological factors.

\section{Material and Methods}

Ethical Approval

This investigation was approved by the $\mathrm{GHC}$ (Hospital Group Conceição) Ethics Committee [CEP-GHC - 045-12] and CEP-UFRGS - 825-462 (Ethics Committee of the Federal University of Rio Grande do Sul). Signed informed consent was obtained from the parents of the participating children. Writing of this article followed the recommendations of STROBE [Strengthening the Reporting of Observational Studies in Epidemiology].

\section{Baseline Assessment}

\section{Participants}

All 674 children born in 2008 (3-4 years old at baseline - in 2011) and registered in one of the GHC primary health care services were eligible. The GHC comprises a hospital and 12 Primary Care Services distributed in the northern area of Porto Alegre, RS, Brazil (a city with 1.5 million inhabitants). All residents in these areas have primary dental care available in public health units near their homes.

The required sample size of 208 children was based - on an estimated caries prevalence of 31\% (using data f from a neighboring city) (12), a bidirectional 0.05 alpha, a 0.10 beta and assuming a $20 \%$ nonresponse rate. The Li sample selection was performed using a table with random numbers maintaining the proportion of children born in each community health unit. The exclusion criterion was: children/mother with cognitive diseases. Baseline data were collected in the years 2011-2012.

\section{Dental Examinations}

Three dentists (PBL, JTP and IB) performed all the dental examinations and applied the questionnaire. The ICDAS (13) was used for dental caries assessment. Both indices in relation to decay and to restorations, and teeth extracted due to caries and unerupted teeth were also used. The three dentists were already familiar with ICDAS, since they had previously been trained using e-Learning Programs (https://www.icdas.org/icdas-e-learning-course). The calibration was performed at the Pediatric Dentistry Clinic of the Federal University of Rio Grande do Sul, Porto Alegre, Brazil. Ten children (different ages with deciduous teeth) were examined and re-examined two weeks later. Tooth surface was considered as the unit of analysis for kappa calculation.

In accordance with ICDAS protocol, all examinations were performed on a clean and dry dental surface. Prophylaxis was conducted with toothbrushes and dental floss. After that, a dental examination was conducted at home, using the house facilities and portable resources: an air compressor (Nevoni, São Caetano, SP, Brazil), a suction device and head light (SS Plus, Maringá, PR, Brazil), a WHO probe (Fava, São Paulo, SP, Brazil), tweezers (Fava), a dental mirror (Sylkap, Curitiba, PR, Brazil) and cotton wool rolls. All personal equipment for biosecurity and infection control was always used. For each dental surface, a code for dental condition (presence and type of restorations) and a code for caries status were recorded.

The participants with caries lesions, restorative needs or pain due to cavitated lesions were scheduled to treatment by dentists from the primary health care where their families belong.

\section{Independent Variables}

A questionnaire was applied to the children's parents with objective questions, self-administered, developed specifically for this research and previously tested in a pilot study about baseline sociodemographic characteristics. - Socioeconomic inventory: mother's age (in years, the obtained mean categorized on the average into: $\leq 32$ years old, $>32$ years old); education (in years of study and then categorized into: $<9$ years of study, 9-11 years of study, $>11$ years); primary caregiver (mother, father, grandmother, sister, aunt, great aunt or another; all responses were categorized into: mother and father/grandmother); marital status was categorized into: single parent (single, divorced or widowed) or married/living together; family monthly income (in absolute values of Real, the obtained mean categorized in tertiles - each tertile corresponded approximately to the value of two and a half minimum wages at baseline - a minimum wage equivalent to 144.11 dollars); satisfaction with income (yes or no), child gender (male or female), prolonged breastfeeding ( $\leq 2$ years or $>2$ years); child's age (in months and subsequently exhibited as average years), number of sons/daughters (collected in numbers and categorized into: $\leq 4$ and $\geq 5$ ), number of people living at home (the total number of people living at home categorized into: $\leq 4$ and $\geq 5$ people) and if the mother worked outside the home in the first two years of the child's life (yes or no).

The sociodemographic data at baseline were used for the analysis, except for the child's age. - Clinical data: ICDAS codes: Relating to surface condition (presence or absence of restorations) and dental caries were collected from each surface and subsequently categorized by the worst clinical condition found in at least one tooth surface of the child: caries free (ICDAS 0), enamel lesions (ICDAS 1, 2 and 3) and dentin lesions (ICDAS 4, 5 and 6). For multivariate analysis, the data were dichotomized as the presence of cavity related to caries - caries free and non-cavitated lesions (ICDAS 0, 1 and 2) and cavitated lesions (ICDAS $\geq 3$ ). 


\section{Follow-up Assessment}

Participants

For the longitudinal evaluation after two years (2014), the telephone numbers and addresses of participants who participated in the baseline study were updated. Telephone contact was made with the children's parents inviting them to participate in the follow-up of the study. When it was not possible to make contact by phone, a letter was sent by the health agents inviting the parents to participate again in the survey. Those who agreed to participate in the monitoring were informed about the objectives and asked to read and sign a new informed consent.

\section{Dental Examinations}

Two dentists (FP and JTP) performed the clinical examinations of the longitudinal evaluation at home, just like in the baseline examinations, using the ICDAS. The data were dichotomized as presence of cavity related to caries - caries free and non-cavitated lesions (ICDAS 0, 1 and 2) and cavitated lesions (ICDAS $\geq 3$ ).

Tooth surface was the unit of analysis for Cohen's kappa calculation.

Similarly to the baseline, the participants identified with caries lesions, restorative needs or pain due to cavitated lesions were directed to dentists from the primary health care to which their families belonged.

\section{Microbiological Analysis}

Stimulated saliva samples were collected from each child in sterile vials and diluted serially in sterile phosphate buffer solution. Aliquots of $25 \mu \mathrm{L}$ of each dilution were plated in duplicate on Mitis salivarius agar (MSB) (Difco, Le Pont de Claix, France) with bacitracin (Sigma Aldrich, St Louis, MO, USA) for determination of S. mutans (MS) and Rogosa SL agar (Himedia, Mumbai, India) for determination of Lactobacillus spp. (LB). The plates were incubated microaerophilically (Fanem, Model $002 \mathrm{CB}$ ) at $37^{\circ} \mathrm{C}$ for 48 and $72 \mathrm{~h}$, respectively. After the incubation periods, the S. mutans and Lactobacillus spp. groups were identified on the basis of colony morphology and counted using a stereoscopic microscope (Model SZ; Olympus, Tokyo, Japan). The counts of microorganisms were expressed in colony forming units (CFU) per milliliter of saliva (CFU/mL saliva).

Based on the density of MS colonies, the findings were classified in four grades: grade $0\left(<10^{4} \mathrm{CFU} / \mathrm{mL}\right)$, grade 1 $\left(10^{4}-10^{5} \mathrm{CFU} / \mathrm{mL}\right)$, grade $2\left(10^{5}-10^{6} \mathrm{CFU} / \mathrm{mL}\right)$ or grade 3 $\left(>10^{6} \mathrm{CFU} / \mathrm{mL}\right.$ ). LB classification was done according to the density of $\mathrm{LB}$ colonies compared with the standard: grade 0 $\left(<10^{3} \mathrm{CFU} / \mathrm{mL}\right)$, grade $1\left(10^{3}-10^{4} \mathrm{CFU} / \mathrm{mL}\right)$, grade $2\left(10^{4}-10^{5}\right.$ $\mathrm{CFU} / \mathrm{mL}$ ) or grade $3\left(>10^{6} \mathrm{CFU} / \mathrm{mL}\right)$. For the data analysis, the results were grouped in two groups: $S$. mutans (grades 0 and $1:<10^{5} \mathrm{CFU} / \mathrm{mL}$ and grades 2 and $3: \geq 10^{5} \mathrm{CFU} / \mathrm{mL}$ ) and Lactobacillus spp. (grades 0 and $1:<10^{4} \mathrm{CFU} / \mathrm{mL}$ and grades 2 and $3: \geq 10^{4} \mathrm{CFU} / \mathrm{mL}$ ) (1).

\section{Dependent Variable}

In this study, in the multivariate analysis, the number of surfaces per child that showed progression of caries at two-year follow-up was the dependent variable, as described below.

The surfaces were categorized into 1 : ICDAS $=0 ; 2$ : ICDAS $=1,2,3 ; 3:$ ICDAS $=4 ; 4:$ ICDAS $=5,6 ; 5$ : filled surfaces; $6:$ ICDAS $=97$. Any change of score for another in the upward direction was considered as a progression. Each of the score changes received one point and the total number of points resulted in the number of surfaces that have progressed in each child. The lesions that maintained the same ICDAS score or changed downward, were considered as non-progression.

\section{Statistical Analysis}

Continuous variables were described using means and standard deviations. Categorical data were presented as counts and percentages. The inter- and intra-examiner reproducibility of the results of clinical exams before and during the study was calculated using Cohen's kappa coefficient.

Unerupted teeth in the baseline assessment (permanent first molars) were considered in the longitudinal evaluation. Exfoliated teeth were considered in the baseline analysis and excluded from the analysis at two-year follow-up. A comparison of participants and non-participants (lost to follow-up) was made using Fisher's exact test and a t-test when required.

The number of caries progressions in each patient was considered to be a counting variable following a Poisson distribution (dependent variable). The rate of caries progression during the observation period was then analyzed using a Poisson regression model with robust standard errors. Results were expressed as exponential coefficents representing rate ratios (RR) with 95\% confidence intervals $(95 \% \mathrm{CI})$. Unadjusted and adjusted analyses were conducted to evaluate independent variables associated with an increased or decreased rate of caries progression. Variables showing a $p<0.20$ in the univariate analysis were included in a backward selection procedure with a critical significance level of $\alpha=0.05$. The overall significance level of the study was set at $\alpha=0.05$. Data were analyzed using SPSS version 22.0.

\section{Results}

A total of 119 children from the 163 examined at baseline were evaluated in the longitudinal study (a 73\% follow-up rate). Figure 1 shown a flow diagram of the 
sampling procedure

A comparison between the data of dropouts $(n=44)$ and participants $(n=119)$ at two-year follow-up was performed and the only significant difference was found in years of mother education $(p=0.001)$ and whether the mother worked during the first two years of a child's life $(p=0.001)$ (Table 1).

At baseline, the inter-examiner Cohen's kappa value was 0.64 (IB), 0.66 (PBL) and 0.73 (JTP) and intra was 0.66 (IB), 0.68 (PBL) and 0.76 (JTP). At the 2-year follow-up, the inter-examiner Cohen's kappa value was 0.67 (FP) and 0.73 (JTP) and intra was 0.73 (FP) and 0.91 (JTP). After half the study sample was achieved, 10 children were revalued to retest the intra- and inter-examiners in both examinations moments. The Cohen's kappa values remained similar to the first tests.

Among the children at two-year follow-up, 50 (42\%) were boys and 69 (58\%) were girls. The gender distribution was similar at both baseline and the follow-up period. The mean age of the participants was $3.41 \pm 0.51$ years at baseline and $5.92 \pm 0.32$ ) at the two-year follow-up. Sociodemographics and children's oral condition at baseline and at two-year follow-up are shown in Table 2.

The incidence of caries lesions was $2.5 \%$. The number $\approx$ of caries-free children decreased from $10.1 \%$ to $7.6 \%$ $\cong$ compared to the baseline data. However, what was more evident was an increase in the severity of lesions, since the dentin lesions (ICDAS 4, 5 and 6) had almost doubled at two-year follow-up.

The associations of socioeconomic variables, breastfeeding duration, oral health status at baseline and quantity of $S$. mutans and Lactobacillus spp. microorganisms with the number of surfaces progression by Poisson regression are shown in Table 3.

The variables that showed statistical significance with the increasing rate of progression at two-year follow-up were marital status, number of CFU/mL in S. mutans saliva and child's oral condition at baseline. For parents who were married/living together at baseline compared to those who were unmarried the rate of caries progression in children was $27 \%$ less.

For children who presented at two-year follow-up less than $10^{5} \mathrm{CFU} / \mathrm{mL}$ of $S$. mutans, compared to those with high counts, the rate of caries progression was 29\% less.

When oral health status was considered, the rate of caries progression was 52\% less for children without cavitated lesions at baseline, compared with those with cavitated lesions.

\section{Discussion}

In the present study, among the 163 participants at baseline, 119 were enrolled for the follow-up, resulting a response rate of $73 \%$. A similar response rate (73.4\%) was found in a longitudinal study in preschool children,

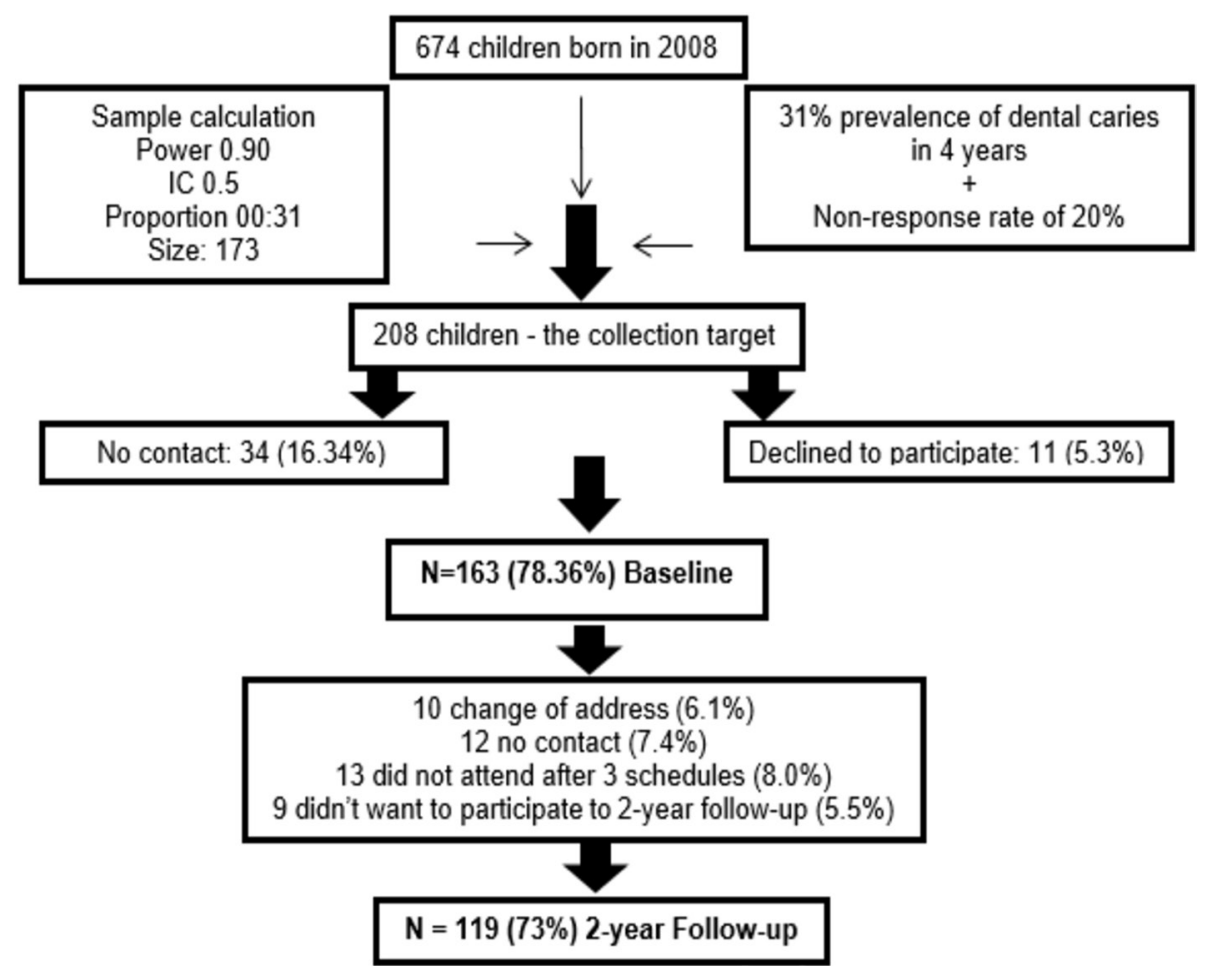

Figure 1. Flow diagram of the study sample.. 
conducted in a city in southern Brazil during the National Children's Vaccination Day (8).

The choice of location for the collection (GHC) was based on the fact that this hospital is part of the Ministry of Health, and assists only patients from SUS (Brazilian Public Health Services), nationally known as the biggest public health provider in southern Brazil.

The GHC has the database of registration of patients regarding families' addresses, phone numbers and components. This database is considered a reference for Brazilian public health services.

The sample in the present study represents families who have access to primary care services in the public health system and also have access to oral health primary care for both children and parents. These people also live in similar locations in the city.

Although these families have full access to a public health service, including dentists who carry out prevention and oral health care, the progression of caries among the children of this study and the increased severity of existing lesions were considered for analysis (14).

This demonstrates that families do not always look for care and free access to a dentist does not necessarily improve the oral health status of the population (14). In this context, programs for information on preventive care for the general and oral health of the population are a major challenge for primary care as well as actions that impact on reducing the prevalence and incidence of caries in preschool children (15).

The fact that families have free access to health services does not mean they look for care. In addition, going to the dentist does not necessarily reduce the incidence of caries. However, access to dental care can improve the quality of life of affected individuals (14).

In this study, one of the variables that remained associated with a decrease in the rate of progression of caries lesions was marital status. Children whose mothers were married or living together at baseline presented a $27 \%$ lower chance of increase in the rate of caries progression by surface, in the two-year follow-up period. Out of the 119 evaluated children, $115(96.6 \%)$ were accompanied by their mothers and among these, 73 $(61.3 \%)$ lived in a nuclear family at baseline. 
The fact that the mother was married or living together at baseline is a protective factor in decreasing the rate of child caries progression. This may be explained because the mother has a fundamental role in the family, especially in relation to health questions and may act as a promoter of multiple information about health for herself and for her family (16).

It was reported that when a child lives alone with his/ her mother or father in a non-nuclear family, there is a greater risk of childhood caries (17). In addition, children living with single mothers who work outside the family

Table 2. Sociodemographics and children's oral condition data of the participants at baseline and at 2-year follow-up

\begin{tabular}{|c|c|c|c|}
\hline Variables & & $\begin{array}{l}\text { Baseline } \\
\mathrm{n}: 119(\%)\end{array}$ & $\begin{array}{c}\text { 2-years } \\
\text { n:119 (\%) }\end{array}$ \\
\hline \multirow{2}{*}{ Child gender } & Male & $50(42)$ & $50(42)$ \\
\hline & Female & $69(58)$ & $69(58)$ \\
\hline Child age - years (mean) & & $\begin{array}{c}3.41 \\
(\mathrm{SD}: \pm 0.51)\end{array}$ & $\begin{array}{c}5.92 \\
(S D: \pm 0.32)\end{array}$ \\
\hline \multirow[b]{2}{*}{ Primary caregiver } & Mother & $114(95.8)$ & 115 (96.6) \\
\hline & $\begin{array}{c}\text { Father/ } \\
\text { Grandmother }\end{array}$ & $5(4.2)$ & $4(3.4)$ \\
\hline $\begin{array}{l}\text { Mother's age } \\
\text { (mean) }\end{array}$ & & $\begin{array}{c}33.94 \\
(\mathrm{SD}: \pm 8.02)\end{array}$ & $\begin{array}{c}36.13 \\
(\mathrm{SD}: \pm 8.10)\end{array}$ \\
\hline \multirow{3}{*}{ Education } & $\begin{array}{l}<9 \text { years } \\
\text { of study }\end{array}$ & $28(23.5)$ & $23(19.4)$ \\
\hline & $\begin{array}{l}9 \text { to } 11 \text { years } \\
\text { of study }\end{array}$ & $57(47.9)$ & $51(42.8)$ \\
\hline & $\begin{array}{l}\text { More than } 11 \\
\text { years of study }\end{array}$ & $34(28.6)$ & $45(37.8)$ \\
\hline \multirow[b]{2}{*}{ Marital status } & Not married & $42(35.3)$ & $46(38.7)$ \\
\hline & $\begin{array}{l}\text { Married/living } \\
\text { together }\end{array}$ & $77(64.7)$ & $73(61.3)$ \\
\hline \multirow{2}{*}{$\begin{array}{l}\text { Mother worked during the } \\
\text { first two years of child's life }\end{array}$} & Yes & $68(57.1)$ & $68(57.1)$ \\
\hline & No & $51(42.9)$ & $51(42.9)$ \\
\hline $\begin{array}{l}\text { Mean monthly income } \\
\text { (American dollars) }\end{array}$ & & $\begin{array}{c}568.87 \\
(\mathrm{SD}: \pm 382.98)\end{array}$ & $\begin{array}{c}598.29 \\
(\mathrm{SD}: \pm 503.79)\end{array}$ \\
\hline \multirow{2}{*}{ Income satisfaction } & Yes & $49(41.2)$ & $33(27.7)$ \\
\hline & No & $70(58.8)$ & $86(72.3)$ \\
\hline \multirow{2}{*}{$\begin{array}{l}\text { Number of people } \\
\text { living at home }\end{array}$} & $\leq 4$ people & $56(47.1)$ & $65(54.6)$ \\
\hline & $>5$ people & $63(52.9)$ & $54(45.4)$ \\
\hline \multirow{2}{*}{ Number of children } & $\leq 4$ & $82(68.9)$ & $79(66.4)$ \\
\hline & $>5$ & $37(31.1)$ & $40(33.6)$ \\
\hline $\begin{array}{l}\text { Children caries } \\
\text { free ICDAS }=0\end{array}$ & & $12(10.1)$ & $9(7.6)$ \\
\hline $\begin{array}{l}\text { Children with enamel } \\
\text { caries ICDAS } 1,2,3\end{array}$ & & $76(63.9)$ & $57(47.9)$ \\
\hline $\begin{array}{l}\text { Children with dentin } \\
\text { caries ICDAS 4,5,6 }\end{array}$ & & $31(26.0)$ & $53(44.5)$ \\
\hline
\end{tabular}

present more caries than working mothers who live in a nuclear family (18).

Another variable associated with the increased rate of progression of caries lesions in the evaluated children were the salivary levels of S. mutans in the two-year follow-up. Studies reported this association with cross-section or longitudinal models (9-10). However, no population-based study showed this finding.

The biological importance of $S$. mutans as the etiologic agent of dental caries in children and as one of the most commonly isolated pathogenic microorganisms in dental plaque and saliva, has been studied for decades in dentistry (19).

A systematic review showed that $S$. mutans levels are strong risk factors for ECC and a longitudinal study confirmed this (20). Furthermore, S. mutans levels in longitudinal study may be as important in predicting new lesions as the previous experience of caries (21).

The variation in the amount of cariogenic microorganisms in children is related to dietary practices, especially to sucrose frequency ingested by the child (19). However, the high salivary levels of S. mutans, as a predictor of caries in childhood, cannot be considered separately. In addition to this, other general and individual risk factors such as past experience of caries should be evaluated.

Lactobacillus species are associated with disease progression, as well as serving as an indirect indicator of the fermentable carbohydrate content. They are more frequently detected in children with severe dental caries because they have more cavities (22).

In the present study, although several lesions presented progression to dentine cavities, no relation was observed in Lactobacillus spp counts and lesion progression.

As dental caries is considered a multifactorial disease, other factors beyond the Lactobacillus spp counts could be also related to the progression of the lesions. Presence of lactobacilli alone in caries lesions or saliva is insufficient to make inferences about their specific contribution to caries development (23).

The incidence of the caries was low (2.5\%), which may be explained by the high prevalence of caries among these children at baseline. However, the progression of the lesions was high (89.9\%), showing an increase in disease severity during the evaluated period. In the present study, the presence of cavitated carious lesions at baseline was also significant for the increased 
rate of progression of caries lesions at two-year follow-up compared to children with initial lesions at baseline.

Similar results were found in several studies, which also showed that the presence of caries lesions at baseline increased the caries increment after the follow-up period $(1,5-8,11,24)$.

Children with cavitated carious lesions at baseline were

Table 3. Univariate and multivariate analyzes showing variables associated with rate of caries progression after a 2-year follow-up period

\begin{tabular}{|c|c|c|c|c|c|c|}
\hline \multirow{2}{*}{ Variables } & \multicolumn{3}{|c|}{ Univariate } & \multicolumn{3}{|c|}{ Multivariate } \\
\hline & $\mathrm{RR}$ & (95\% IC) & $p$ & $\mathrm{RR}$ & (95\% IC) & $p$ \\
\hline \multicolumn{7}{|l|}{ Mother age } \\
\hline$\leq 32$ years old & 1,25 & $(0.87-1.78)$ & 0.213 & & - & \\
\hline$>32$ years old & 1.00 & & & & & \\
\hline \multicolumn{7}{|l|}{ Mother education } \\
\hline$<9$ years & 1.46 & $(0.89-2.39)$ & 0.129 & & - & \\
\hline 9 to 11 years & 1.18 & $(0.80-1.74)$ & 0.380 & & & \\
\hline$>11$ years & 1.00 & & & & & \\
\hline \multicolumn{7}{|l|}{ Family income at Baseline } \\
\hline 1st tertile & 1.86 & $(1.25-2.76)$ & 0.002 & & - & \\
\hline 2nd tertile & 1.37 & $(0.91-2.05)$ & 0.125 & & & \\
\hline 3rd tertile & 1.00 & & & & & \\
\hline \multicolumn{7}{|l|}{ Satisfaction with income } \\
\hline $\begin{array}{l}\text { Yes } \\
\text { No }\end{array}$ & $\begin{array}{l}0.84 \\
1.00\end{array}$ & $(0.56-1.26)$ & 0.403 & & - & \\
\hline \multicolumn{7}{|l|}{ Marital status } \\
\hline Married/Living Together & 0.62 & $(0.44-0.86)$ & 0.005 & 0.73 & $(0.54-0.98)$ & $0.040^{*}$ \\
\hline Not married & 1.00 & & & 1.00 & & \\
\hline \multicolumn{7}{|l|}{$\begin{array}{l}\text { Mother worked outside the home } \\
\text { in the first } 2 \text {-years of the child }\end{array}$} \\
\hline Yes & 1.16 & $(0.82-1.63)$ & 0.393 & & - & \\
\hline No & 1.00 & & & & & \\
\hline \multicolumn{7}{|l|}{ Prolonged breastfeeding } \\
\hline$\leq 2$-years & 0.63 & $(0.39-1.00)$ & 0.054 & & - & \\
\hline >2-years & 1.00 & & & & & \\
\hline $\begin{array}{l}\text { Lactobacillus spp. } \\
\quad<10^{4} \mathrm{CFU} / \mathrm{mL} \\
\geq 10^{4} \mathrm{CFU} / \mathrm{mL}\end{array}$ & $\begin{array}{l}0.74 \\
1.00\end{array}$ & $(0.47-1.16)$ & 0.199 & & - & \\
\hline $\begin{array}{l}\text { Streptococcus mutans } \\
<10^{5} \mathrm{CFU} / \mathrm{mL} \\
\geq 10^{5} \mathrm{CFU} / \mathrm{mL}\end{array}$ & $\begin{array}{l}0.47 \\
1.00\end{array}$ & $(0.33-0.68)$ & $<0.001$ & $\begin{array}{l}0.71 \\
1.00\end{array}$ & $(0.52-096)$ & $0.031^{*}$ \\
\hline \multicolumn{7}{|l|}{ Oral health status at Baseline } \\
\hline Caries free/non-cavitated lesions & 0.40 & $(0.30-0.54)$ & $<0.001$ & 0.48 & $(0.37-062)$ & $<0.001^{*}$ \\
\hline Cavitated lesions (ICDAS $\geq 3$ ) & 1.00 & & & 1.00 & & \\
\hline
\end{tabular}

$\mathrm{RR}$, rate ratio obtained in Poisson regression model. ${ }^{*} \mathrm{p}<0.05$. associated with an increasing rate of caries progression when compared to caries-free children.

An increase in the progression of dental caries in children with cavitated carious lesions at baseline was also demonstrated in other studies $(8,24)$.

Based on the obtained results, new longitudinal studies with a longer follow-up period in this age group should be conducted to increase knowledge about the factors associated with the progression of caries lesions.

In view of the significant progression of caries, programs for the promotion and encouragement of oral health and the subsequent prevention of disease in preschool children and their caregivers should be deployed in the public health system.

At baseline, children's saliva samples were not collected due to the young age of the participants and the difficulty of performing the sample collection, since in many cases it was necessary to stimulate the saliva with chewing gum.

The limitation of the study was the absence of interproximal radiographic and/or spacing of the teeth to the examinations. This fact may have underestimated caries lesions in the proximal surfaces. In relation to access, it was learned how many times the patients were attended in the public health service. However, there is lack of more detailed information about calls scheduling attempts to such access.

After a two-year follow-up, in the population connected to a primary health care was noted that the previous history of the disease with clinical evidence of cavity and the higher S. mutans counts in the children's saliva and the mothers' marital status at baseline were associated with 
an increasing rate of caries lesions progression .

\section{Resumo}

A cárie precoce na infância (CPI) acomete crianças em todo o mundo e apresenta alta prevalência e severidade em pré-escolares. Diferentes fatores sociais, biológicos e comportamentais constituem uma rede de fatores causais da CPI. 0 objetivo deste estudo foi avaliar a associação entre as variáveis socioeconômicas e presença de cárie na linha de base e a presença de Streptococcus mutans e Lactobacillus spp. com a progressão de lesões de cárie após dois anos de acompanhamento em um grupo de crianças. Na avaliação inicial, foram avaliadas 163 crianças (3-4 anos de idade) pertencentes a 12 unidades básicas de saúde do Grupo Hospitalar Conceição (GHC, Porto Alegre, RS, Brasil). Após dois anos, foram reavaliadas 119 crianças. Os exames clínicos foram realizados por examinadores calibrados usando os critérios ICDAS. Um questionário sociodemográfico foi aplicado aos pais das crianças e amostras de saliva foram coletadas de crianças para análise microbiológica. Foram realizadas estatísticas descritivas e regressão multivariada de Poisson na análise estatística. Os fatores associados com a progressão de cárie foram o estado marital das mães $(p=0,040)$ e a presença de lesões cavitadas no início do estudo e uma maior contagem de $S$. mutans $(p=0,031)$ após dois anos de acompanhamento. A progressão de cárie em pré-escolares pertencentes às unidades de atenção primária em saúde foi diretamente associada com o estado marital das mães, presença de lesões cavitadas na linha de base e maior contagem de $S$. mutans após dois anos de acompanhamento.

\section{References}

1. Lee HJ, Kim JB, Jin BH, Paik DI, Bae KH. Risk factors for dental caries in childhood: a five-year survival analysis. Community Dent Oral Epidemiol 2015;43:163-171.

2. Bönecker M, Ardenghi TM, Oliveira LB, Sheiham A, Marcenes W. Trends in dental caries in 1- to 4-year-old children in a Brazilian city between 1997 and 2010. Int J Paediatr Dent 2010;20:125-131.

3. Pucca GA Jr, Gabriel M, de Araujo ME, Almeida FC. Ten years of a national oral health policy in Brazil: innovation, boldness, and numerous challenges. J Dent Res 2015;94:1333-1337.

4. Peres MA, Oliveira Latorre MR, Sheiham A, Peres KG, Barros FC, Hernandez $P G$, et al.. Social and biological early life influences on severity of dental caries in children aged 6 years. Community Dent Oral Epidemiol 2005;33:53-63.

5. Tagliaferro EP, Pereira AC, Meneghim MC, Ambrosano GM. Assessment of dental caries predictors in a seven-year longitudinal study. J Public Health Dent 2006;66:169-173.

6. Ismail Al, Sohn W, Lim S, Willem JM. Predictors of dental caries progression in primary teeth. J Dent Res 2009;88:270-275.

7. Cortellazzi KL, Tagliaferro EP, Pereira SM, Ambrosano GM, Guerra LM,

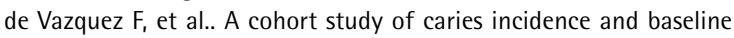
socioeconomic, clinical and demographic variables: a Kaplan-Meier survival analysis. Oral Health Prev Dent 2013;11:349-358.

8. Guedes RS, Piovesan C, Floriano I, Emmanuelli B, Braga MM, Ekstrand $\mathrm{KR}$, et al.. Risk of initial and moderate caries lesions in primary teeth to progress to dentine cavitation: a 2-year cohort study. Int J Paediatr
Dent 2016;26:116-124.

9. Mattos-Graner RO, Corrêa MS, Latorre MR, Peres RC, Mayer MP. Mutans streptococci oral colonization in 12-30-month-old Brazilian children over a one-year follow-up period. J Public Health Dent 2001;61:161167.

10. Zhou Y, Yang JY, Lo EC, Lin HC. The contribution of life course determinants to early childhood caries: a 2-year cohort study. Caries Res 2012;46:87-94.

11. Parisotto TM, Santos MN, Rodrigues LK, Costa LS. Behavior and progression of early carious lesions in early childhood: a 1-year followup study. J Dent Child 2012;79:130-135.

12. Ferreira, SH, Beria, JU, Kramer, PF, Feldens, EG, Feldens, CA. Dental caries in 0- to 5-year-old Brazilian children: prevalence, severity, and associated factors. Int J Paediatr Dent 2007;17:289-296.

13. Ismail Al, Sohn $W$, Tellez M, Amaya A, Sen A, Hasson $H$, et al.. The International Caries Detection and Assessment System (ICDAS): an integrated system for measuring dental caries. Community Dent Oral Epidemiol 2007;35:170-178.

14. Peres MA, Peres KG, de Barros AJ, Victora CG. The relation between family socioeconomic trajectories from childhood to adolescence and dental caries andassociated oral behaviours. J Epidemiol Community Health 2007;61:141-145.

15. Plutzer K, Keirse MJ. Influence of an intervention to prevent early childhood caries initiated before birth on children's use of dental services up to 7 years of age. Open Dent J 2014;30;8:104-108.

16. Oliveira ML, Bastos $\mathrm{AC}$. Health care practices in family context: a comparative case study. Psicol Reflex Crit 2000;13:97-107.

17. Hallett $K B, O^{\prime}$ Rourke PK. Early childhood caries and infant feeding practice. Community Dent Health 2002;19:237-242.

18. Plutzer K, Keirse MJ. Influence of first-time mothers' early employment on severe early childhood caries in their child. Int J Pediatr 2012;2012:820680.

19. Parisotto TM, Stipp R, Rodrigues LK, Mattos-Graner RO, Costa LS, Nobre-Dos-Santos M. Can insoluble polysaccharide concentration in dental plaque, sugar exposure and cariogenic microorganisms predict early childhood caries? A follow-up study. Arch Oral Biol. 2015;60:1091-1097.

20. Parisotto TM, Steiner-Oliveira C, Silva CM, Rodrigues LK, Nobre-dosSantos M. Early childhood caries and mutans streptococci: a systematic review. Oral Health Prev Dent 2010;8:59-70.

21. Gao $X, \mathrm{Hsu} C \mathrm{CY}$, Loh $\mathrm{T}$, Hwarng $\mathrm{B}$, Koh D. Role of microbiological factors in predicting early childhood caries. Pediatr Dent 2014;36:348-354.

22. I van Houte J, Gibbs G, Butera C. Oral flora of children with "nursing bottle caries". J Dent Res 1982;61:382-385

23. Li Y, Argimón S, Schön CN, Saraithong P, Caufield PW. Characterizing diversity of lactobacilli associated with severe early childhood caries: a study protocol. Adv Microbiol 2015;5:9-20.

24. André Kramer AC, Skeie MS, Skaare AB, Espelid I, Ostberg AL. Caries increment in primary teeth from 3 to 6 years of age: a longitudinal study in Swedish children. Eur Arch Paediatr Dent 2014;15:167-173.

Received August 6, 2016 Accepted December 5, 2016 